\title{
Factors that influence treatment adherence of tuberculosis patients living in Java, Indonesia
}

This article was published in the following Dove Press journal:

Patient Preference and Adherence

4 August 2009

Number of times this article has been viewed

\author{
Bagoes Widjanarko ${ }^{1,2}$ \\ Michelle Gompelman ${ }^{3}$ \\ Maartje Dijkers ${ }^{4}$ \\ Marieke J van der Werf ${ }^{5,6}$ \\ 'Magister program of Health \\ Promotion, Graduate study \\ of Diponegoro University, Indonesia; \\ ${ }^{2}$ Faculty of Public Health, Diponegoro \\ University, Indonesia; ${ }^{3}$ Healthcare \\ and Culture, VU Medical Center, \\ Free University, Amsterdam, \\ The Netherlands; ${ }^{4}$ Academic Medical \\ Center, University of Amsterdam, \\ The Netherlands; ${ }^{5} \mathrm{KNCV}$ \\ Tuberculosis Foundation, The Hague, \\ The Netherlands; ${ }^{6}$ Center for Infection \\ and Immunity Amsterdam (CINIMA), \\ Academic Medical Center, University \\ of Amsterdam, The Netherlands
}

Correspondence: Marieke J van der Werf KNCV Tuberculosis Foundation,

PO Box I46, 250 I CC The Hague,

The Netherlands

$\mathrm{Tel}+3 \mathrm{I} 704270963$

Fax +3I 703584004

Email vanderwerfm@kncvtbc.nl
Background and objective: Due to nonadherence of tuberculosis (TB) patients to treatment, complications may arise and if remaining infectious, these patients may infect other people with TB. To obtain information about factors associated with nonadherence, we performed a study comparing adherent and nonadherent TB patients.

Methods: Adherent and nonadherent patients randomly selected from hospital records in one urban and two rural districts were interviewed using semi-structured questionnaires. Key informant interviews were done with TB nurses and doctors.

Results: The most frequently mentioned reason for nonadherence to treatment was feeling better. Although the drugs were given free of charge, many patients were nonadherent because of lack of money. Social support was considered very important for adherence. The study indicated that some patients had a negative image about the health care staff, treatment, and quality of medication.

Conclusion: Treatment adherence of TB patients receiving treatment in hospitals in Central Java might be improved by providing health education about treatment duration and side effects, facilitating procedures for receiving treatment free of charge and reducing costs of transportation and consultation. Qualified friendly health care staff able to motivate patients might further improve adherence.

Keywords: tuberculosis, adherence, DOTS treatment, patient knowledge, Indonesia

\section{Introduction}

Indonesia ranks third on the list of countries with the highest number of estimated incident tuberculosis (TB) cases. ${ }^{1}$ TB is responsible for $7.7 \%$ of the total disease burden and approximately 91,000 people die each year of TB in Indonesia. ${ }^{1}$ To fight against the high burden of TB, Indonesia has implemented the Directly Observed Therapy, Short-Course (DOTS) strategy in 1995 and has now reached coverage of $100 \%{ }^{1}$ In 2006, 5\% of new smear-positive TB patients treated under the DOTS strategy defaulted from treatment in Indonesia. ${ }^{1}$ Engagement of the private and public hospitals and chest clinics in the DOTS strategy has resulted in an increase in adherence of patients with TB treatment. ${ }^{2}$ DOTS expansion into government and private hospitals in Yogyakarta resulted in a decrease in treatment default. ${ }^{3}$

A systematic synthesis of qualitative studies showed that treatment adherence depends on four major factors: structural factors; the social context; health service factors; and personal factors. ${ }^{4}$ On Java adherence of TB patients that receive DOTS treatment in the public and private hospitals is low (personal communication). Due to nonadherence, patients will not be cured of their disease. This gives complications such 
as development of severe disease and drug resistance. ${ }^{5}$ Also, these nonadherent patients remain infectious and there is a longer period of time when they can infect other people. ${ }^{6}$

To the best of our knowledge, qualitative research that systematically looks at the reasons for nonadherence of TB patients in the hospitals has not yet been conducted in Indonesia. Research conducted in Timor-Leste systematically studied the barriers and the enabling factors for successful implementation of the DOTS strategy. The study, performed in one rural and one urban area with the lowest treatment completion rates, concluded that local cultural practices and knowledge as well as socioeconomic factors contribute to less than optimal adherence to TB treatment. ${ }^{7}$

To obtain information about factors that are associated with nonadherence in Indonesia, we performed a study comparing risk factors for nonadherence, behaviors, and perceptions of adherent TB patients with those of nonadherent TB patients in public and private hospitals.

\section{Methods}

The study was carried out in three districts: two rural (Kabupaten Semarang and Grobogan) and one urban (Kota Semarang), in Central Java, Indonesia. These districts were chosen because they were reachable by car within four hours and included enough hospitals that applied the DOTS strategy. We included all four public and nine private hospitals that provided TB treatment and that were sensitized to the DOTS strategy. In these hospitals, patients with at least two positive smear results were treated with combi pack or fixed-dose combination drugs and in most cases treatment was observed and monitored by specially educated TB nurses. The aim was for every patient to have an observer, though this was not always realized.

An exploratory, comparative, and qualitative descriptive study design was used to identify structural factors (side effects, duration), patient factors (poverty, gender), social context (stigma), and health care service factors that influence adherence to TB treatment in the Indonesian context. Patients diagnosed with smear-positive TB in 2006 or 2007 and aged 16 to 80 years, who stopped TB treatment or interrupted treatment for two weeks or more (nonadherent) and patients who were still following treatment at the time of the study or completed treatment (adherent) were eligible for inclusion. Patients that were still on treatment had to have completed at least four months of treatment to be eligible for inclusion. We aimed at interviewing 30 adherent (15 from public and 15 from private hospitals) and 30 nonadherent TB patients (15 from public and 15 from private hospitals).
The district TB officers who are responsible for recording and reporting of TB patients in the district provided information about TB patients that were eligible for inclusion in the study. Additional information on adherence was obtained from the TB nurses in the hospitals. The patients were divided into three groups, adherent patients (treatment completed or still on treatment), nonadherent patients (defaulted or interrupted treatment for two weeks or more), and other patients (died, failed, and transfered out). We included TB patients from the adherent and nonadherent groups, starting with those that were most recently registered.

To obtain the perspective of health care workers about adherence to TB treatment, we interviewed key informants (TB nurses and lung specialists). Key informants were randomly chosen from a list with all TB nurses and lung specialists of the included hospitals. The aim was to interview two TB doctors and two TB nurses from the private hospitals and two TB doctors and two TB nurses from the public hospitals. The key informants were also asked to provide information about the organization of the health care system.

For the patient interviews, semi-structured flexible in-depth interview guidelines were designed based on information obtained from literature and from the key informant interviews. Before the interview was conducted, the patient was informed about the purpose of the interview and asked to sign the informed consent form. The interviews were conducted at the house of the patient with the support of two Indonesian-speaking research assistants. Each interview was recorded on audio tape. The recording was transcribed and transcripts were scrutinized to identify emerging and recurrent themes. Frequency of different themes and categories of answers was counted to identify key issues and trends. With SPSS software (v.15.0 for Windows; SPSS Inc., Chicago, IL, USA), we performed statistical analysis using Chi-square tests or if appropriate Fisher's exact tests to compare factors associated with (non)adherence.

The study was approved by the Diponegoro University in Semarang, Indonesia and the ethical review committee of the University of Amsterdam, The Netherlands.

\section{Results}

A total of 250 patients, 107 from private hospitals and 143 from public hospitals, were eligible for inclusion in the study. We had to trace $130 \mathrm{~TB}$ patients to obtain interview results from $63(48 \%)$ patients (31 adherent and 32 nonadherent patients) (Table 1). Of the 67 patients that could not be interviewed, $19(15 \%)$ had died and 41 (32\%) patients had moved away or were untraceable. Seven patients were not at home 
Table I The characteristics of interviewed patients of private and public hospitals in Central Java 2006-2007

\begin{tabular}{|c|c|c|c|c|c|}
\hline \multirow[t]{2}{*}{ Variable } & \multirow{2}{*}{$\begin{array}{l}\text { Total } \\
(n=63) \\
n(\%)\end{array}$} & \multicolumn{2}{|c|}{ Adherent } & \multicolumn{2}{|c|}{ Nonadherent } \\
\hline & & $\begin{array}{l}\text { Private } \\
(n=15) \\
n(\%)\end{array}$ & $\begin{array}{l}\text { Public } \\
(n=16) \\
n(\%)\end{array}$ & $\begin{array}{l}\text { Private } \\
(n=16) \\
n(\%)\end{array}$ & $\begin{array}{l}\text { Public } \\
(n=16) \\
n(\%)\end{array}$ \\
\hline \multicolumn{6}{|l|}{ Gender } \\
\hline - Male & $35(56)$ & $6(40)$ & $10(63)$ & II (69) & $8(50)$ \\
\hline - Female & $28(44)$ & $9(60)$ & $6(38)$ & $5(3 \mathrm{I})$ & $8(50)$ \\
\hline Age in years & 42.9 & 42.5 & 41.9 & 41.4 & 46.1 \\
\hline - $\leq 40$ & $30(48)$ & $8(53)$ & $9(56)$ & $8(50)$ & $5(3 \mathrm{I})$ \\
\hline - $>40$ & $33(52)$ & $7(47)$ & $7(44)$ & $8(50)$ & II (69) \\
\hline \multicolumn{6}{|l|}{ Education* } \\
\hline - None & $6(10)$ & $2(13)$ & I (6.3) & $2(13)$ & I (6.3) \\
\hline - Elementary & $27(43)$ & $9(60)$ & $3(19)$ & $7(44)$ & $8(50)$ \\
\hline - High school or more & $29(46)$ & $4(27)$ & II (68) & $7(44)$ & $7(44)$ \\
\hline Income in rupiah & $552.487,5$ & 646.200 & 770.000 & 213.750 & 580.000 \\
\hline \multicolumn{6}{|l|}{ Religion } \\
\hline - Muslim & $61(97)$ & $13(87)$ & $16(100)$ & $16(100)$ & $16(100)$ \\
\hline - Christian & $2(3.2)$ & $2(13)$ & 0 & 0 & 0 \\
\hline \multicolumn{6}{|l|}{ Area } \\
\hline - Urban & $35(56)$ & $6(40)$ & $12(75)$ & $7(44)$ & $10(63)$ \\
\hline - Rural & $28(44)$ & $9(60)$ & $4(25)$ & $9(56)$ & $6(38)$ \\
\hline \multicolumn{6}{|l|}{ Type of tuberculosis } \\
\hline - New & $44(70)$ & $13(87)$ & $14(88)$ & $9(56)$ & $8(50)$ \\
\hline - Retreatment & $19(30)$ & $2(13)$ & $2(13)$ & $7(44)$ & $8(50)$ \\
\hline
\end{tabular}

Note: *One compliant patient from a public hospital didn't answer this question.

after several attempts to find them. Some patients (6.9\%) were not available for interview because they had moved to another city for work. These were mainly younger patients.

\section{Patient factors}

\section{Personal characteristics}

We did not find apparent differences among the personal characteristics of the adherent and nonadherent patients (Table 1). A total of 63 patients, 35 males (55\%) and 28 females $(45 \%)$, were interviewed. Adherence of female patients and male patients was comparable $(p=0.62)$. Fifty percent of the interviewed male patients reported that their wife was their treatment observer, while female patients frequently (53\%) reported that they were their own observer. The average age of the adherent patients was 42.3 (range 21-82) and nonadherent patients 43.2 (range 17-78). Also the education level of adherent patients ( $48 \%$ high school or more) did not differ from that of nonadherent patients (44\% high school or more) $(p=0.80)$. Only two of the interviewed patients were Christian, both adherent; all the other interviewed patients were Muslim. From the adherent patients, four were retreatment patients and from the nonadherent patients, 15 were retreatment patients that had stopped their treatment again $(p=0.005)$.

\section{Costs and financial burden}

Although DOTS treatment is free of charge, $30 \%$ of patients that resided in rural areas had to pay a substantial amount of money for transportation to the hospital. Additionally, if treated in a private hospital, patients also had to pay a doctor's fee. Forty percent of the interviewed nonadherent patients mentioned that costs played an important role in determining whether they adhered to the treatment.

If I had the money, I would have gone back to the hospital already.

- Five nonadherent patients

The average salary of the nonadherent patients in the private hospitals was three times lower than the adherent patients. In public hospitals, this difference was less apparent.

\section{Knowledge, beliefs, and attitudes about TB}

Most patients (85\%) knew that TB is an infectious disease. However, only nine patients mentioned that they got TB by infection from another person (Table 2). Thirteen patients 
Table 2 Knowledge of the TB patients about their disease and the cause

\begin{tabular}{|c|c|c|c|c|c|c|}
\hline \multirow[t]{2}{*}{ Knowledge } & \multicolumn{2}{|l|}{ Total } & \multicolumn{2}{|c|}{ Adherent } & \multicolumn{2}{|c|}{ Nonadherent } \\
\hline & $\begin{array}{l}\text { Private } \\
(n=3 I) \\
n(\%)\end{array}$ & $\begin{array}{l}\text { Public } \\
(n=32) \\
n(\%)\end{array}$ & $\begin{array}{l}\text { Private } \\
(n=I 5) \\
n(\%)\end{array}$ & $\begin{array}{l}\text { Public } \\
(n=16) \\
n(\%)\end{array}$ & $\begin{array}{l}\text { Private } \\
(n=16) \\
n(\%)\end{array}$ & $\begin{array}{l}\text { Public } \\
(n=16) \\
n(\%)\end{array}$ \\
\hline \multicolumn{7}{|l|}{ Cause* } \\
\hline - Don't know & $9(29)$ & $4(9.5)$ & $4(27)$ & I (5.3) & $5(3 \mathrm{I})$ & $3(13)$ \\
\hline - Stress/tired & $10(32)$ & $3(7.1)$ & $4(27)$ & 0 & $6(38)$ & $3(13)$ \\
\hline - Smoking & $4(13)$ & $4(9.5)$ & $3(20)$ & I (5.3) & I (6.3) & $3(13)$ \\
\hline - Workplace & $4(13)$ & $6(14)$ & $2(13)$ & $2(I I)$ & $2(I 3)$ & $4(17)$ \\
\hline - Not TB & $3(10)$ & 0 & 0 & 0 & $3(19)$ & 0 \\
\hline - Infectious & $2(6.5)$ & $7(17)$ & 0 & $5(26)$ & $2(13)$ & $2(8.7)$ \\
\hline - Night wind/dust & $4(13)$ & $5(12)$ & $4(27)$ & $2(I I)$ & 0 & $3(13)$ \\
\hline - Behavior in youth & 0 & $3(7.1)$ & 0 & 0 & 0 & $3(13)$ \\
\hline - Other & $3(9.7)$ & $10(24)$ & $2(13)$ & $8(42)$ & I (6.3) & $2(8.7)$ \\
\hline \multicolumn{7}{|l|}{ Duration treatment } \\
\hline - Six months & $20(65)$ & $29(91)$ & $12(80)$ & $15(94)$ & $8(50)$ & $14(88)$ \\
\hline - Less or more than six months & $7(23)$ & $2(6.3)$ & I (6.7) & $\mathrm{I}(6.2)$ & $6(38)$ & $\mathrm{I}(6.2)$ \\
\hline - No idea & $4(13)$ & I (3.I) & $2(13)$ & 0 & $2(13)$ & $\mathrm{I}(6.2)$ \\
\hline \multicolumn{7}{|l|}{ Consequences if stop treatment* } \\
\hline - Can't be cured & $15(48)$ & $6(19)$ & $9(60)$ & $5(29)$ & $6(38)$ & I (7.I) \\
\hline - Relapse & $5(16)$ & $4(12)$ & $\mathrm{I}(6.7)$ & $2(12)$ & $4(25)$ & $2(14)$ \\
\hline - Dying & $4(13)$ & $5(16)$ & $2(13)$ & $4(24)$ & $2(13)$ & I (7.I) \\
\hline - No idea & $10(32)$ & $7(23)$ & $5(33)$ & $2(12)$ & $5(3 \mid)$ & $5(36)$ \\
\hline - Start again & 0 & $9(29)$ & 0 & $4(24)$ & 0 & $5(36)$ \\
\hline
\end{tabular}

Note: *More than one answer possible.

Abbreviation: TB, tuberculosis.

thought their disease was caused by stress even though they also reported that it was an infectious disease. Another 13 patients attributed their disease to other reasons such as eating spicy food, drinking water chilled with ice cubes, or to heredity factors.

With the exception of two patients, all patients included from public hospitals knew the duration of the treatment and they all knew they had to finish and take the medication every day to be completely cured. Half of the nonadherent patients from the private hospitals didn't know the duration of treatment, whereas $87 \%$ of the adherent patients reported that the duration was at least six months.

The doctor only told me to come back when the pills are finished.

- Nonadherent elderly male TB patient from an urban hospital

Role of the traditional healer

Ten patients used herbs or massages in combination with their TB treatment. They said that this didn't influence their adherence. Two patients, who were feeling worse from the DOTS treatment, tried a traditional healer after they had stopped their DOTS treatment.

My family brought me to a special "dukun", who is known in the whole area for his healing skills.

- Nonadherent male

\section{Reasons for stopping or continuing treatment}

Most nonadherent patients gave multiple reasons for quitting their treatment (Table 3). Feeling better was the most frequently mentioned reason (47\%). The second reason, often in combination, was lack of money (44\%). Almost $20 \%$ of the nonadherent patients actually thought they were healthy at the moment of interviewing. On the other hand there were also some nonadherent patients that stopped because they were feeling worse $(13 \%)$ or experienced side effects $(28 \%)$. Thirty percent of the nonadherent patients had not received instructions from the health care worker about the side effects that could be expected to occur and what to do. 
Table 3 Reasons for stopping DOTS treatment mentioned by nonadherent TB patients and reasons why they might stop DOTS treatment mentioned by adherent TB patients in Central Java

\begin{tabular}{|c|c|c|c|c|}
\hline \multirow[t]{2}{*}{ Reason* } & \multicolumn{2}{|c|}{$\begin{array}{l}\text { Reasons }(n=56) \text { by nonadherent } \\
\text { patients }(n=32)\end{array}$} & \multicolumn{2}{|c|}{$\begin{array}{l}\text { Reasons }(n=4 I) \text { by adherent } \\
\text { patients }(n=3 I)\end{array}$} \\
\hline & $\begin{array}{l}\text { Public } \\
n=16 \\
n(\%)\end{array}$ & $\begin{array}{l}\text { Private } \\
n=16 \\
n(\%)\end{array}$ & $\begin{array}{l}\text { Public } \\
n=16 \\
n(\%)\end{array}$ & $\begin{array}{l}\text { Private } \\
n=15 \\
n(\%)\end{array}$ \\
\hline \multicolumn{5}{|l|}{ Personal reasons } \\
\hline - Feeling better & $7(44)$ & $8(50)$ & $2(13)$ & 0 \\
\hline - Getting bored & $2(13)$ & I (6.3) & $9(56)$ & $5(33)$ \\
\hline - No concern about health & 0 & 0 & $\mathrm{I}(6.3)$ & $\mathrm{I}(6.7)$ \\
\hline - Healthy & I (6.3) & 0 & 0 & I (6.7) \\
\hline - Feeling worse & 0 & $2(13)$ & 0 & 0 \\
\hline \multicolumn{5}{|l|}{ Money } \\
\hline - No money & $5(3 I)$ & $9(56)$ & $3(19)$ & $3(20)$ \\
\hline - Work abroad & I (6.3) & $\mathrm{I}(6.3)$ & 0 & 0 \\
\hline Transportation & $4(25)$ & $2(13)$ & $2(13)$ & 0 \\
\hline \multicolumn{5}{|l|}{ Health care facility } \\
\hline - Health care system: Procedure & I (6.3) & 0 & 0 & 0 \\
\hline - Incompetence of health care staff & $I(6.3)$ & $\mathrm{I}(6.3)$ & 0 & 0 \\
\hline - Bad service & $I(6.3)$ & I (6.3) & 0 & 0 \\
\hline \multicolumn{5}{|l|}{ Treatment } \\
\hline - Side effects & $3(19)$ & $6(38)$ & I (6.3) & I (6.7) \\
\hline - Many or big pills & 0 & I (6.3) & I (6.3) & $4(27)$ \\
\hline Don't know & 0 & 0 & $2(13)$ & $5(33)$ \\
\hline
\end{tabular}

Note: *More than one reason mentioned is possible.

Abbreviations: DOTS, directly observed therapy, short-course; TB, tuberculosis.

My urine turned red; I thought it was blood caused by the medication. I thought it was safer to stop the medication.

- Nonadherent male patient

When the adherent patients were asked why they still followed treatment, the majority said because they wanted to be cured. A few patients (15\%) mentioned they were still on treatment only to please their family.

\section{Community and household support}

Around $60 \%$ of the interviewed patients reported to have a treatment observer. Most often this was the partner or a family member. In general the observer was considered essential by the patients. Without an observer they would forget to take their medication and wouldn't be able to get new pills every month.

Half of the elderly and low educated people had to stop treatment because they had no social support or no observer that checked if they take their medication, bring them to the hospital or collected new medication from the hospital. Also elderly and low educated patients frequently didn't understand the doctors' instructions and had no transport to take them to the hospital. A few of the younger educated people didn't find an observer useful.

\section{Stigma attached to tuberculosis}

In the rural areas, $80 \%$ of the TB patients were not secretive about their disease. One third of the patients initially only told their family and a few neighbors about their disease, but after a while more and more neighbors found out about their 'lung disease'. Sometimes the whole neighborhood knew that the patient had 'lung disease'. The neighbors and family members were often stimulating and helping the patients with their treatment. The interviewed patients said they felt really supported by them.

In the urban areas, $25 \%$ of the patients from the private hospitals did hide their disease; especially the more wealthy and higher educated patients. There was only one patient that said that people kept a distance because they were aware of the disease.

In the beginning they didn't talk to me so much anymore, but after a while they got used to it and did (sic) normal again.

- Female adherent patient 


\section{Health care service factors}

We performed eight key informant interviews: four with a lung specialist and four with a TB nurse. According to the interviewed health care workers, the DOTS program is well implemented in the included hospitals.

Each diagnosed patient receives instructions from the doctor or nurse about the disease, how to take the medication and some side effects. TB medication is provided free of charge.

- Half of the interviewed TB nurses and doctors Two of the nurses reported that they tried to find a treatment observer who could assist the patient in taking medication. The TB nurses checked the patients' physical status during regular visits to the hospital and assessed whether they were still adherent. Not all visits of TB patients were recorded in the patient files. The nurses explained that patients that were referred often got lost.

If a referred patient never arrives at the health center we have no way to notice this, since there is no good communication between the hospitals to crosscheck if the patients ever received treatment.

- Two TB nurses

Additionally, three nurses did not trace patients that were late for their appointment. There was only one private hospital where the nurses went to the patients' house to put them back on therapy.

\section{Health care workers}

Most of the interviewed patients (80\%) were positive about the health care staff. The interviewed patients said to have great confidence in the TB nurses and doctors and felt supported by them. One third of the nonadherent patients had experienced problems in communication with the hospital staff. According to these patients the doctors or nurses were sometimes unfriendly and could have little patience.

I'm very scared of the doctor, because he made fun of me. He said to me that he had to blow up my lungs, because there were big holes in them.

- Nonadherent female patient

Half of the interviewed patients expressed the wish to know more about their disease and the treatment. Two of the interviewed nurses and one of the doctors said that they sometimes gave less information to patients that were old and/or low educated, because they thought the patient wouldn't understand them. Furthermore, they thought that providing too much information would confuse the patients and make them more concerned about their disease.
When I tried to ask the doctor a question, he just said to take the pills every day.

- Nonadherent female patient

\section{Organization health care system}

Treatment of patients by the public hospitals was often complicated by the organization of the health care system. Patients who cannot afford to pay for treatment can get treatment free of charge. To be eligible for free treatment, they first need to collect an exemption card, sometimes at a place different from where they receive treatment. Additionally, this exemption card needs to be prolonged every month. Patients reported that it took them too much money and time to prolong the card every month. Patients also reported that they did not want free treatment because they believed that free treatment was of lower quality compared with treatment for which they would have had to pay.

If I have the exemption card, they will give me cheaper or expired drugs.

- Young adherent patient

At the hospital two nurses said the service is the same for all patients, only sometimes they give different brands of the drugs to patients with an exemption card.

\section{Discussion}

The study identified factors that influence treatment adherence in patients treated in public and private hospitals in Central Java, Indonesia. Patients' behavior, health care workers' behavior, and society's behavior all play an important role. A key finding of our study is that most patients were not adherent to their treatment because they started to feel better, and this was often in combination with lack of money to pay for fees and transportation. Another finding is that some patients, especially the nonadherent patients, were not satisfied with the behavior of the health care staff. Health care workers' behavior can influence treatment adherence as reported by studies done in Nepal ${ }^{8,9}$ and Mexico. ${ }^{10}$ These three studies all concluded that a good health care worker-patient relationship may contribute to better adherence. Nepalese patients mentioned side effects and failure of the health care system also as common reasons to stop treatment on top of poverty and feeling better. ${ }^{9}$ This study is comparable to our study since it was conducted in hospitals.

According to a study in Zambia, patient behavior is largely influenced by the knowledge of the patients about their disease and treatment. ${ }^{11}$ A comparable study done in Turkey showed that patients who were provided with knowledge of treatment had a higher adherence rate. ${ }^{12}$ These studies 
seem to confirm the importance of providing patients with adequate information about the type of treatment, duration of treatment, and side effects in order to ensure adherence. Patients in our study reported that the treatment observer and the health care worker were very important to keep them motivated. In an Indian study the patients also confirmed the importance of social support. ${ }^{13}$

According to the World Health Organization (WHO) guidelines, treatment observation can be performed by a health worker or a trained and supervised member of the community. ${ }^{14,15}$ In general, it is not advised that members of the patient's family serve as treatment observers. ${ }^{14}$ In our study the observer was a family member in all but one case. This is the normal procedure in Indonesia. Although not recommended by WHO there are studies that show that family members can be equally effective in treatment observation. ${ }^{16,17}$

In the rural areas stigma around TB seemed to have no influence on adherence, although patients always referred to their disease as 'lung disease' instead of tuberculosis. In the urban areas some patients did hide their condition especially the wealthier patients, although they would normally inform their employer. Other studies have shown that TB is stigmatized because it is believed that TB is hereditary or caused by a killing in the family. ${ }^{7,18}$ Stigma seemed to play a less important role in adherence to treatment of the patients in our study, who seemed to be more influenced by lack of money and insufficient knowledge. In patients from Timor-Leste cost of transport, difficulty of accessing treatment and time away from work or school, were the most important factors that influenced adherence. ${ }^{7}$ Knowledge and beliefs were less important factors in this study.

A Nigerian study provided evidence that free treatment is very important to ensure patient adherence.$^{19}$ In concordance with these results our study shows that a large number of the interviewed poor patients could not finish their treatment because they had to pay for the drugs, for transportation or for the doctor, even though they were motivated to take the treatment. Given that high perceived costs and unfriendly behavior of health care staff was associated with nonadherence, the proper implementation of the DOTS strategy in a hospital, which includes free drugs, a patients' own observer, and special trained and qualified health care staff, should improve adherence.

This study revealed a difference between the number of adherent and nonadherent patients that were retreatment patients. A study in India that also identified risk factors for nonadherence of tuberculosis patients to DOTS had a similar outcome. ${ }^{20}$ They concluded that retreatment patients have a high risk for nonadherence.

\section{Limitations of the study}

The patient interviews and key informant interviews were performed with the help of interpreters. This influenced the flow of the interview and might have caused misinterpretation of answers. However, it is unlikely that the main findings of our study would have been different when interpretation would not have been necessary. We frequently cross-checked the translation of the patients' answers when listening to the audiotapes. After doing our analysis we also discussed our findings with the interpreters and they agreed with the main outcomes of the study.

The patients were interviewed at home so that they would feel comfortable. Although all the patients seemed quite at ease and willing to cooperate, it was difficult to be sure they gave honest answers. The questions were asked again or formulated differently if they appeared to be misunderstood. Answers could only be cross-checked with the hospital data; most of the information was not verifiable. Cross checking sometimes showed that a patient was listed as nonadherent in the hospital, but reported to be still on treatment during the interview. Many interviews, especially in the rural areas, were done in the presence of the family. It seemed that in these areas the family members could have an important role in influencing the treatment of the patient, both negatively and positively. The family also provided additional information about the patient and their role in the treatment.

\section{Conclusion}

Most TB patients stopped DOTS treatment because they were starting to feel better often in combination with lack of money, side effects or getting bored of the pills. In addition, the procedure to get treatment free of charge was complicated and time consuming. Some nonadherent patients considered the behavior of health care staff rude or unfriendly. Factors that facilitated adherence were social support including the support of a treatment observer and health education about treatment.

Treatment adherence of TB patients receiving treatment in hospitals in Central Java can be improved by providing health education about treatment duration and side effects, facilitating procedures for receiving treatment free of charge and reducing costs of transportation and consultation. Qualified, friendly health care staff able to motivate patients can further improve adherence. 


\section{Acknowledgments}

We are grateful to the University of Diponegoro in Semarang, and the Provincial health office of Central Java for the approval of our research. We are also grateful to Anantalia Widyastari and Any Setyawati for their guidance and support during the time of interviewing and we also like to thank Jan Voskens (Consultant Unit International of the KNCV) for his assistance in generating our research. This study was partially funded by the KNCV, Tuberculoses Foundation. The authors report no conflicts of interest in this work.

\section{References}

1. World Health Organization. WHO Report 2009. Global Tuberculosis Control Epidemiology, Strategy, Financing. Geneva, Switzerland: World Health Organization; 2009.

2. World Health Organization. Public-Private Mix for DOTS implementation. PPM DOTS in Indonesia: A Strategy for Action. Mission Report. Geneva, Switzerland: World Health Organization; 2003.

3. Irawati SR, Basri C, Arias MS, et al. Hospital DOTS linkage in Indonesia: a model for DOTS expansion into government and private hospitals. Int J Tuberc Lung Dis. 2007;11(1):33-39.

4. Munro SA, Lewin SA, Smith HJ, Engel ME, Fretheim A, Volmink J. Patient adherence to tuberculosis treatment: A systematic review of qualitative research. PloS Med. 2007;4(7):e238.

5. Weis SE, Slocum PC, Blais FX. et al. The effect of directly observed therapy on the rates of drug resistance and relapse in tuberculosis. N Engl J Med. 1994;330(17):1179-1184.

6. Chakrabarti B, Davies PD. Key issues in multidrug-resistant tuberculosis. Future Microbiol. 2007;2:51-61.

7. Martins N, Grace J, Kelly PM. An ethnographic study of barriers to and enabling factors for tuberculosis treatment adherence in Timor Leste. Int J Tuberc Lung Dis. 2008;12(5):532-537.

8. Mishra P, Hansen EH, Sabroe S, Kafle KK. Adherence is associated with the quality of professional-patient interaction in Directly Observed Treatment Short-course, DOTS. Patient Educ Counsel. 2006;63(1-2):29-37.
9. Wares DF, Singh S, Acharya AK, Dangi R. Non-adherence to tuberculosis treatment in the eastern Tarai of Nepal. Int J Tuberc Lung Dis. 2003;7(4):327-335.

10. Alvarez Gordillo GC, Alvarez Gordillo JF, Dorantes Jimenez JE. Educational strategy for improving patient compliance with the tuberculosis treatment regimen in Chiapas, Mexico. Rev Panam Salud Publica. 2003;14(6):402-408.

11. Kaona F, Tuba M, Siziya S, Sikaona L. An assessment of factors contributing to treatment adherence and knowledge of TB transmission among patients on TB treatment. BMC Public Health. 2004;4:68.

12. Halim H, Rasyid A, Ahmad Z. Evaluation of four years hospital implementation of DOTS strategy (1998-2002). Acta Med Indones. 2006;38(3):130-134.

13. Barnhoorn F, Adriaanse H. In search of factors responsible for noncompliance among tuberculosis patients in Wardha District, India. Soc Sci Med. 1992;34(3):291-306.

14. World Health Organization. Treatment of Tuberculosis. Guidelines for National Programmes. Geneva, Switzerland: World Health Organization; 2003.

15. Pungrassami $\mathrm{P}$, Chongsuvivatwong V. Are health personnel the best choice for directly observed treatment in southern Thailand? A comparison of treatment outcomes among different types of observers. Trans R Soc Trop Med Hyg. 2002;96(6):695-699.

16. World Health Organization. Community Contribution to TB Care: Practice and Policy. Geneva, Switzerland: World Health Organization; 2003.

17. Newell JN, Baral SC, Pande SB, Bam DS, Malla P. Family-member DOTS and community DOTS for tuberculosis control in Nepal: clusterrandomised controlled trial. The Lancet. 2006;367(9514):903-909.

18. Long NH, Johansson E, Diwan VK, Winkvist A. Different tuberculosis in men and women: beliefs from focus groups in Vietnam. Soc Sci Med. 1999;49:815-822

19. Erhabor GE, Aghanwa HS, Yusuph M. Adebayo RA, Arogundade FA, Omidiora A. Factors influencing compliance in patients with tuberculosis on Directly Observed Therapy at Ilefe, Nigeria. East Afr Med J. 2000;77(5):235-239.

20. Gopi PG, Vasantha M, Muniyandi M, Chandrasekaran V, Narayanan PR. Risk factors for non-adherence to directly observed treatment (DOT) in a rural tuberculosis unit, South India. Indian $J$ Tuberc. 2007;54(2):66-70.
Patient Preference and Adherence

\section{Publish your work in this journal}

Patient Preference and Adherence is an international, peer-reviewed, open access journal that focusing on the growing importance of patient preference and adherence throughout the therapeutic continuum. Patient satisfaction, acceptability, quality of life, compliance, persistence and their role in developing new therapeutic modalities and compounds to

\section{Dovepress}

optimize clinical outcomes for existing disease states are major areas of interest. This journal has been accepted for indexing on PubMed Central. The manuscript management system is completely online and includes a very quick and fair peer-review system. Visit http://www.dovepress.com/ testimonials.php to read real quotes from published authors. 